\title{
"Eliminar os indesejáveis": uma lógica de ação para o policiamento dos argelinos em Paris (1944-1962)
}

\author{
Emmanuel Blanchard \\ Université de Versailles-Saint-Quentin-en-Yvelines (UVSQ) \\ Saint-Quentin-en-Yvelines, França \\ blanchard@cesdip.fr
}

\section{RESUMO}

$\mathrm{O}$ artigo trata da relação estabelecida entre imigrantes argelinos na França com o Estado e, sobretudo, com a polícia. Durante os primeiros anos da década de 1940 houve igualdade de direitos entre os "muçulmanos" (argelinos) e os "europeus" (franceses). Cidadãos de pleno direito a partir do momento em que entravam na França, argelinos gozavam de liberdade de circulação entre as duas margens do Mediterrâneo e podiam se instalar livremente na metrópole. Contudo, a partir da guerra de libertação da Argélia houve um aumento da imigraçáo para a França, o que gerou protestos entre os franceses. Do fim da Segunda Guerra Mundial até o término da guerra de independência argelina, a hierarquia policial resistiu ao "mito da igualdade dos direitos". Impotente diante do fluxo imigratório, a polícia executava uma política de confronto aos "indesejáveis", qualificativo utilizado para designar as populaçóes argelinas estigmatizadas, cuja presença no espaço público era percebida como um problema.

Palavras-chave: polícia; imigração; relaçôes coloniais; Argélia; França.

\begin{abstract}
The article deals with the relationship between Algerian immigrants, the French State, and particularly the Police. In the first years of the 1940's, there was equality of rights between "Muslims" (Algerians) and "Europeans" (the French). Acquiring full citizenship at the moment they entered France, Algerians enjoyed travelling freedom between the two edges of the Mediterranean. However, the liberation war in Algeria triggered an increase in immigration to France, generating protests among the French. From the end of II World War to the end of the independence war in Algeria, Police hierarchy resisted to the "myth of rights' equality". Impotent to deal with the immigration flow, Police implemented a confrontation policy with the "undesirable," i.e., the stigmatized Algerian population in France, whose presence in the public space was perceived as a problem.
\end{abstract}

Keywords: police; immigration; colonial relationships; Algeria; France.

* Tradução do francês de Raquel Campos.

Artigo recebido em 10 de maio de 2012 e aceito em 19 de outubro de 2012. 


\section{A solução mais simples — que consistiria em internar todos os FMA comprometidos ou suspeitos - não é nem materialmente viável, nem politicamente recomendável. \\ Prefeitura de Polícia, relatório de 29 de julho de 1957, APP HA 65.}

De 1944 a 1962, os imigrantes argelinos na França não estavam submetidos ao controle migratório. Entre 1944 e 1947, um conjunto de textos organizara o reconhecimento da cidadania francesa dos colonizados da Argélia e a igualdade de direitos entre os "muçulmanos" e os "europeus". ${ }^{1}$ Nos departamentos da Argélia, as regras eleitorais — um "colégio duplo" que conferia um peso dez vezes maior ao voto dos "europeus" que ao dos "muçulmanos" - limitaram singularmente o alcance dessas disposiçóes, mas elas tiveram consequências muito importantes para os candidatos à emigração. Cidadãos de pleno direito a partir do momento em que entravam na França, eles gozavam de inteira liberdade de circulação entre as duas margens do Mediterrâneo e podiam se instalar livremente na metrópole. Os serviços policiais especializados, inspirados naqueles que funcionavam nos departamentos argelinos e que, desde a metade dos anos 1920, tratavam-nos como "indígenas", haviam sido suprimidos durante a Liberação.

Conjugadas à redução dos custos do transporte, essas reformas e esses novos direitos deram um alcance inédito à emigração, a partir do final de 1946. As chegadas tornaram-se então maciças — com um saldo migratório médio anual de cerca de 20 mil pessoas entre 1947 e 1962 . Apesar de estarem entre os migrantes que os especialistas não desejavam ver instalados na França, ${ }^{2}$ os argelinos se tornaram, depois dos italianos, a maior comunidade no país (cerca de 350 mil pessoas em 1962).

Essa "imigração imposta" ${ }^{3}$ pelo contexto colonial não demorou a gerar protestos. Do fim da Segunda Guerra Mundial até o término da guerra de independência argelina, a hierarquia policial não cansou de lutar contra esse "mito da igualdade dos direitos". ${ }^{4}$ Ela exigia medidas que lhe permitissem controlar, prender e expulsar os argelinos, sem entrave jurídico nem controle do Poder Judiciário. A partir da metade dos anos 1950 - e sobretudo a partir de 1958 - as repercussóes metropolitanas da guerra de independência argelina permitiram que a Prefeitura de Polícia fosse ouvida e obtivesse ganho de causa em algumas questóes.

\section{Restringir a circulação, uma constante do controle policial dos argelinos}

A liberdade de circulação, concedida no âmbito da defesa do império colonial, veio opor-se aos princípios da ordem pública na metrópole, como eram interpretados pelas forças da ordem. O processo de "pauperização"s de muitos migrantes argelinos, tornados vagabundos, e o uso do crime como forma de subsistência por alguns entre eles alimentaram assim a onda de recriminaçóes dos cidadãos e as

\footnotetext{
${ }^{1}$ BLEVIS, Laure. Les avatars de la citoyenneté en Algérie coloniale ou les paradoxes d'une catégorisation. Droit et société, n. 48, p. 557-580, 2001.

${ }^{2}$ WEIL, Patrick. La France et ses étrangers. L'aventure d'une politique de l'immigration, 1938-1991. Paris: Calmann-Lévy, 1991. p. 54-59.

${ }^{3}$ Georges Mauco formulou essa distinção entre “imigração desejada” e “imigração imposta”, às vésperas da Segunda Guerra Mundial, para distinguir os "trabalhadores dos refugiados". WEIL, Patrick. Georges Mauco, expert en immigration: ethnoracisme et antisémitisme fielleux. In: TAGUIEFF, Pierre-André (Dir.). L'antisémitisme de plume, 1940-1944. Études et documents. Paris: Berg International Éditeurs, 1999. p. 267-276.

${ }^{4}$ Agendas de Roger Léonard, prefeito de polícia (1947-1951), 24 de novembro de 1948. Archives de Sciences Po, assento RL 1.

${ }^{5}$ TILLION, Germaine. Algérie 1957. Paris: Minuit, 1957. p. 40-41.
} 
campanhas de imprensa qualificadas de "racistas" pelos raros defensores dos argelinos. ${ }^{6}$ Elas reforçaram estereótipos coloniais que o novo ordenamento jurídico e político era incapaz de enfraquecer. Diante da recusa das autoridades políticas de rediscutir a liberdade de circulação, a hierarquia policial tentou restringi-la por meio de diversos artifícios, muitos dos quais já haviam sido postos em prática no entreguerras. A obrigação de fazer exames médicos e de se vacinar, de reunir uma caução equivalente às eventuais taxas de repatriamento e de possuir um documento de identidade uniforme, com fotografia, foi assim evocada como um meio de evitar a partida dos mais pobres. A necessidade de não infringir a Constituição, de levar em consideração os representantes políticos dos "franceses muçulmanos da Argélia", as concorrências e a inércia administrativas fizeram com que, antes do início da guerra de independência argelina, nenhuma disposição tivesse realmente restringido essa liberdade de circulação.

Impossibilitada de controlar a imigração argelina, a polícia tentou limitar suas possibilidades de circulação na metrópole por meio de dois artifícios: a organização de sua mínima visibilidade no espaço público e a tentativa de fazê-los retornar para a Argélia. Para isso, ela recorreu amplamente ao repertório de açôes da polícia dos "indesejáveis": esse qualificativo era comumente utilizado para designar as populaçốes estigmatizadas, cuja presença no espaço público era percebida como um problema. Fora de qualquer quadro jurídico, estabeleceram-se, então, métodos de ação que nada tinham de inéditos. De prisôes em massa a internaçóes nas instalaçôes da polícia, de fichamentos a deportaçôes, de controles de identidade a detençóes administrativas, os argelinos partilhavam a sorte dos outros "cidadãos diminuídos"8 (prostitutas, vadios, homossexuais...) e de um subproletariado nacional cujo controle constituiu durante muito tempo o essencial do trabalho da polícia.' Seu estatuto protegia-os, entretanto, de medidas como a expulsão ou a deportação, que ameaçavam os estrangeiros que infringissem a ordem pública ou não satisfizessem as expectativas dos empregadores. Os argelinos não tiveram tampouco que conhecer as provaçôes das longas internaçôes administrativas. Essas privaçôes da liberdade por iniciativa exclusiva da polícia eram, contudo, praticadas na mais absoluta ilegalidade, em relaçáo a outros cidadãos nacionais, como os vadios conduzidos à Maison Départamentale de Nanterre (uma espécie de hospital prisão para os "sem-teto") ou as prostitutas hospitalizadas mediante coação na antiga prisão Saint-Lazare. Os representantes dos "franceses muçulmanos da Argélia" no parlamento e seus diversos apoios políticos (especialmente dentro do Partido Comunista) eram então suficientemente ouvidos para que esse tipo de medida não lhes fosse aplicada. A hierarquia policial não deixou, contudo, de se referir a uma internação administrativa, que ela desejava impor, mas que não se tornou realidade senão alguns anos mais tarde.

Não obstante esses limites impostos à arbitrariedade policial, os argelinos estavam longe de ser objeto de um tratamento preferencial. Eles eram frequentemente detidos para averiguaçáo — tanto nos finais de semana, a fim de evitar que a visibilidade desses trabalhadores que viviam na sombra não indispusesse os outros transeuntes parisienses, ${ }^{10}$ como quando ocorriam convocaçóes para mobilização do Movimento pelo Triunfo das Liberdades Democráticas (MTLD), a fachada legal do Partido do Povo Argelino, independentista. A repressão das manifestaçóes nacionalistas indica precisamente a que ponto

\footnotetext{
${ }^{6}$ Eram particularmente os comunistas que denunciavam os jornais "racistas". L'Algérie en France, jornal do Partido Comunista Francês (PCF), esteve à frente dessas denúncias.

${ }^{7}$ BLANCHARD, Emmanuel. L'encadrement des algériens de Paris (1944-1954), entre contraintes juridiques et arbitraire policier. Crime, histoire \& sociétés, v. 11, n. 1, p. 5-25, 2007.

${ }^{8}$ A expressão "cidadãos diminuídos" era utilizada com frequência por representantes do PCF para qualificar os argelinos da metrópole. Ver, sobretudo, as intervençóes dos deputados do PCF nos conselhos de Paris e do Sena: Bulletin Municipal Officiel-Conseil Municipal, p. 342, 18 jul. 1947; Bulletin Municipal Officiel-Conseil Général, p. 170, 20 mar. 1953.

${ }^{9}$ ROBERT, Philippe. Le citoyen, le crime, l'État. Genebra: Droz, 1999. p. 23-35.

${ }^{10}$ BOGART, Léo. Les algériens en France, adaptation réussie et non réussie. In: INED. Français et immigrés. Paris: PUFIned, 1954. p. 48.
} 
a violência policial em relação aos colonizados não estava restrita aos territórios ultramarinos. ${ }^{11} \mathrm{O}$ fato é que o "cheque em cinza" 12 concedido nessa época pelo poder político a uma polícia responsável pela manutenção da ordem social e colonial, mesmo ao custo de violaçôes da legalidade, não era uma carta branca: alguns contrapesos limitavam a arbitrariedade policial. Eles diminuíram consideravelmente quando as repercussóes metropolitanas da guerra da Argélia se fizeram sentir.

\section{Desejos policiais satisfeitos graças à guerra}

A partir de 1955, a Prefeitura de Polícia de Paris viu assim ser aceita a maioria de suas reivindicaçóes que haviam se chocado, nos anos anteriores, com a oposição do Ministério do Interior e, de modo geral, do poder político.

Os argelinos foram assim progressivamente fichados e registrados. O arquivo dos "Norte-africanos” — parcialmente destruído, em 1940, para que não caísse nas mãos do ocupante alemão — não havia sido substituído na Liberação. Para preencher essa lacuna, a Prefeitura de Polícia realizou, sob pretexto de pesquisas sociais e recenseamentos, inúmeras operaçóes que visavam a um melhor conhecimento dos "meios norte-africanos". A partir de agosto de 1953, um novo serviço, supostamente dedicado a combater a delinquência de rua — a Brigada das agressóes e violências $(\mathrm{BAV})^{13}$ —, multiplicou as batidas policiais, às vezes com o apoio de fotógrafos, a fim de produzir um novo arquivo. Ele permaneceu muito incompleto, uma vez que a Prefeitura de Polícia não dispunha de nenhuma prerrogativa legal que obrigasse todos os argelinos a contatá-la. Com o início da guerra, essa dimensão limitada da identificação tornou-se uma desvantagem que os benefícios políticos esperados de um relativo respeito dos textos com valor constitucional, que definiam o estatuto dos argelinos, já não podiam contrabalançar. É à luz disso que devem principalmente ser analisadas medidas como a criação da carteira nacional de identidade, em outubro de 1955. Em março de 1956, quando foi instituído o novo regime de circulação entre as duas margens do Mediterrâneo, ${ }^{14}$ a carteira nacional de identidade tornou-se obrigatória para obter uma autorização de viagem. Esses textos legislativos não podiam ser integralmente aplicados devido, sobretudo, a restriçôes administrativas e burocráticas, como a imperfeição do registro civil na Argélia, a insuficiência dos efetivos policiais... Eles objetivavam principalmente obrigar os argelinos a se fazerem conhecidos dos serviços policiais. A partir de 1958, a Prefeitura de Polícia e a Segurança Nacional reconheceram expressamente que o registro da totalidade dos argelinos era um objetivo prioritário. Pela primeira vez, essa ambição foi acompanhada do estabelecimento de um aparelho militar-policial, os Serviços de Assistência Técnica aos Franceses Muçulmanos da Argélia (SAT-FMA), ${ }^{15}$ que pretendiam subordinar toda ação social aos imperativos de manutenção da ordem e da "guerra contrarrevolucionária".

\footnotetext{
${ }^{11}$ De 1937 a 1962, os únicos manifestantes mortos em Paris pelas forças da ordem foram argelinos (28 de maio de 1952, 14 de julho de 1953). A essas sete vítimas parisienses devem ser somadas aquelas (ao menos três) que foram mortas na província, particularmente em maio de 1952. TARTAKOWSKY, Danielle. Les manifestations de rue en France. Paris: Fayard, 1997. p. 633-635.

12 Tomamos esse conceito emprestado do criminologista canadense Jean-Paul Broder, que o utiliza para situações nas quais os poderes públicos permitem que a polícia exerça livremente suas modalidades de repressão, mesmo extralegais, desde que não surjam controvérsias políticas.

${ }^{13}$ BLANCHARD, Emmanuel. Police judiciaire et pratiques d'exception pendant la guerre d'Algérie. Vingtième Siècle. Revue d'histoire, n. 90, p. 9-41, avr./juin 2006.

${ }^{14}$ A partir dessa data a livre circulação é suprimida e torna-se necessário obter uma autorização de viagem, emitida nas delegacias de polícia, para ir à Argélia.

${ }^{15}$ Sobre os serviços de assistência técnica aos FMA (SAT-FMA), cujos funcionários e métodos foram importados da Argélia: HOUSE, Jim; MACMASTER, Neil. Paris 1961: algerians, state terror and post-colonial memories. Oxford: Oxford University Press, 2006. p. 66-77.
} 
As forças da ordem obtiveram sucesso também em termos de controle da circulação, de possibilidades de confinamento e de meios de deportar os "indesejáveis". Em setembro de 1958 e em outubro de 1961, a promulgação de toques de recolher restritos apenas aos "trabalhadores argelinos" foi, sem dúvida, a medida mais emblemática dessa reviravolta na relação de forças entre a polícia e os órgãos políticos e jurídicos que deveriam controlá-la. ${ }^{16}$ A polícia parisiense obteve, com violação do direito - tratava-se de uma discriminação inconstitucional —, algumas das prerrogativas em termos de restrição da liberdade de ir e vir reclamadas por ela havia muitos anos. Para além das proibiçóes de sair à rua durante a noite, ela objetivava também paralisar o tráfego de automóveis por meio de controles constantes dos veículos e das possibilidades de apreendê-los sem ordem judicial.

No mesmo sentido de restrição da liberdade de ir e vir dos "suspeitos", as autoridades da Prefeitura recorreram também ao confinamento domiciliar: os indivíduos visados deveriam se apresentar semanalmente nas delegacias de suas localidades para receberem um visto em seus carnês de confinamento. As autoridades policiais sabiam que essa medida era pouco eficaz, preferindo-lhe as novas possibilidades de internação. Em 1957-1958, dois textos autorizaram a internação administrativa na metrópole — internação praticada na Argélia desde abril de 1955, após ter sido decretado estado de emergência. A lei de 26 de julho de 1957 estendeu à metrópole uma parte dos poderes especiais adotados para a Argélia em 16 de março de 1956. Ela abriu a possibilidade de confinar toda pessoa condenada com base nas "leis sobre os grupos de combate e milícias privadas". Esse confinamento, que se concretizava por meio da internação em um dos quatro "centros de confinamento vigiados" (CArs), ${ }^{* 17}$ abertos na esteira desse movimento, estava portanto condicionado a uma condenação judicial anterior. Ela permitiu ao Ministério do Interior deter irrestritamente os "indivíduos perigosos" libertados da prisão e gerou o reaparecimento de campos de internação (os últimos, fechados em 1946, haviam abrigado pessoas acusadas de colaboração durante a Segunda Guerra Mundial) no território metropolitano. Embora reclamados pela polícia, eles eram percebidos como verdadeiras escolas de quadros nacionalistas (o que eram, efetivamente), e até mesmo "campos de repouso", ${ }^{18}$ segundo Michel Debré, primeiro-ministro bastante atento às modalidades de uma repressão que ele considerava insuficiente.

A despeito desses novos poderes, a polícia não se conformava com permanecer dependente do Poder Judiciário. O ministro da Justiça, Edmond Michelet, foi regularmente contestado pelo chefe de governo, que no verão de 1961 obteve sua substituição por Bernard Chenot, adepto integral da política de desconsiderar os direitos das pessoas. Uma portaria de outubro de 1958 permitiu também que uma parte dos casos fosse julgada por tribunais militares, estabelecendo um modo de se contornar sistematicamente todas as autoridades judiciárias. O "laxismo" destas últimas, regularmente denunciado em tempos de paz, parecia insuportável para a hierarquia policial no momento em que a unidade e a integridade nacionais eram ameaçadas por uma "rebeliáo". A nomeação de Maurice Papon para a direção da Prefeitura de Polícia, em março de 1958, foi um dos fatores que permitiram que novos meios lhe fossem concedidos. Um de seus projetos inspirou fortemente a portaria de 7 de outubro de 1958, que dava às autoridades policiais e administrativas novos poderes de internação. Essas disposiçóes ampliavam consideravelmente o escopo dos indivíduos suscetíveis de sofrer uma medida de confinamento: todas as "pessoas perigosas para a segurança pública, devido à ajuda material, direta ou indireta, que dão aos rebeldes dos departamentos argelinos" estavam sujeitas a ela.

\footnotetext{
${ }^{16}$ THENAULT, Sylvie. Les couvre-feux en région parisienne pendant la guerre d'Algérie. Politix, n. 84, p. 67-85, 2008. *No original, Centres de Assignation à Résidence Surveillés. (N.T.).

17 THENAULT, Sylvie. Personnel et internés dans les camps d'internement de la guerre d'Algérie. Entre stéréotypes coloniaux et combat pour l'indépendance. Politix, n. 69, p. 63-81, mar. 2005.

${ }^{18}$ Carta do primeiro-ministro, Michel Debré, a Edmond Michelet, ministro da Justiça, 4 dez. 1959, D DE 22, arquivos de Sciences Po.
} 
Precisóes posteriores confirmaram, contudo, que apenas os "franceses muçulmanos da Argélia" eram visados por essas medidas privativas de liberdade cuja promulgação era grandemente facilitada. A portaria previa, com efeito, que um simples decreto da Prefeitura, assinado com base em relatórios dos RG,* era suficiente para conduzir indivíduos que deviam ser "vigiados" para estabelecimentos penitenciários ou "centros de triagem"19 abertos em departamentos em que a "colônia norte-africana" estava fortemente estabelecida. Havia apenas um verdadeiro limite aos poderes exorbitantes das autoridades policiais: a internação prefeitoral normalmente não podia ultrapassar quinze dias. Ela podia, entretanto, ser prorrogada, através de um decreto ministerial de confinamento, por tempo indeterminado. Este último era tomado com base apenas em relatórios policiais. A polícia não viu, aliás, seus poderes muito reduzidos pela criação da Comissão de Verificação das Medidas de Segurança Pública, prevista no artigo $3^{\circ}$ da portaria de 7 de outubro de 1958. Embora alguns de seus avisos transmitidos ao ministro do Interior tenham produzido efeito, ela não exerceu senão um vago controle a posteriori e um papel consultivo. Seu poder foi tão reduzido quanto o da Comissão de Salvaguarda dos Direitos e Liberdades Individuais, encarregada de investigar as torturas e desaparecimentos na Argélia. ${ }^{20}$

Ao final da vigência do decreto prefeitoral de confinamento, os indivíduos submetidos a um decreto ministerial eram transferidos para um dos quatro Cars da metrópole. ${ }^{21}$ Diante do desejo policial de deter o máximo de indivíduos, as dificuldades de coordenação entre múltiplos ministérios (Justiça, Interior, Defesa), ${ }^{22}$ o custo dessa política e a falta de respeito aos prazos de assinatura pelo ministro do Interior foram os únicos limites à utilização dos confinamentos "sem duração predeterminada". Essas consideraçóes levaram Émile Pelletier, ministro do Interior, a relembrar, em outubro de 1958:

Está fora de questáo neste momento - embora ela possa parecer um meio cômodo de se livrar de todos os elementos FSNA* [franceses de origem norte-africana] considerados perigosos - recorrer a uma política maciça de internação, devido à capacidade ainda muito reduzida, tanto na metrópole quanto na Argélia, dos centros de alojamento destinados a recebê-los. ${ }^{23}$

Esse dispositivo foi, entretanto, plenamente montado nos anos seguintes. Durante quase três anos, ele dominou as veleidades de enviar os "suspeitos" para além do Mediterrâneo.

\footnotetext{
* RG é a abreviatura de Renseignements Généraux (Informações Gerais), serviço de informação francês cujo nome oficial era Direction Centrale des Renseignements Généraux. (N.T.)

${ }^{19}$ Os "centros de triagem" eram lugares de detenção e às vezes de interrogatório dos indivíduos confinados pelos prefeitos por um período de quinze dias. Denominados também de "centros de trânsito" ou "centros de identificação", na maioria das vezes caracterizados por um simples endereço, de modo a ocultar sua verdadeira utilidade, eles eram geralmente localizados no interior das delegacias ou de outros prédios da polícia.

${ }^{20}$ Sobre essas comissóes, ver: BRANCHE, Raphaëlle. La commission de sauvegarde pendant la guerre d'Algérie: chronique d'un échec annoncé. Vingtième Siècle. Revue d'histoire, n. 61, p. 14-29, 1999. E da mesma autora: La seconde commission de sauvegarde des droits et libertés individuels. In: AFHJ. La justice en Algérie 1830-1962. La Documentation Française, 2005, p. 237-246.

${ }^{21}$ THENAULT, Sylvie (Dir.). Vadenay, Saint-Maurice l'Ardoise, Thol, le Larzac. L'internement en France pendant la guerre d'indépendance algérienne [dossier]. Matériaux pour l'Histoire de Notre Temps, n. 92, p. 1-72, oct./déc. 2008.

${ }^{22}$ A gendarmaria era encarregada das transferências dos confinados dos centros de triagem para os CARS.

* Français de souche nord-africaine. (N.T.)

${ }^{23}$ Circular no 577 do Ministério do Interior referente à aplicação da portaria de 7 de outubro de 1958. Circular enviada a todos os prefeitos em 15 de outubro de 1958.
} 


\section{Argélia, terra de banimento}

Os repatriamentos para os departamentos argelinos eram o outro horizonte do trabalho policial. Desde o final dos anos 1940, as disposiçôes relativas à expulsão de vadios para seus departamentos ou países de origem foram invocadas e utilizadas como um meio de se livrar de alguns "ociosos". As disposições regulamentares nessa matéria foram modificadas repetidamente, no intuito de ampliar as categorias de indivíduos afetados pelos dispositivos controlados por diferentes ministérios. Para os argelinos, cidadãos franceses, esse retorno só deveria ser possível se eles expressassem seu desejo de maneira explícita. A Prefeitura de Polícia tentava, no entanto, aplicar-lhes as disposiçôes relativas aos estrangeiros, pois estes podiam ser repatriados a contragosto. Se repatriamentos forçados foram efetivamente praticados, eles tiveram, entretanto, um alcance restrito, devido principalmente a questóes de divisão dos custos financeiros - as comunas e departamentos argelinos deviam contribuir com as taxas e normalmente não estavam inclinados a fazê-lo. Tais disposiçóes conheceram, contudo, algum sucesso, visto que o número de repatriamentos decuplicou entre 1950 e 1954, atingindo um total de 6.500 só neste ano. ${ }^{24}$ Mas eles não aumentaram muito ao longo da guerra da Argélia. Seu número era limitado devido à implicação de diferentes ministérios e ao custo do pagamento do transporte. Quando pareceu necessário demonstrar que o poder sabia ser duro com os nacionalistas, centenas de "expulsões para o aduar de origem" foram realizadas sem que qualquer disposição jurídica fosse invocada. Foi o que ocorreu após os conflitos da Goutte d'Or em agosto de $1955^{25}$ e após as manifestaçôes de outubro de 1961.

A portaria de 7 de outubro de 1958 abria, assim, a possibilidade de recorrer ao "afastamento, espécie de banimento administrativo". ${ }^{26} \mathrm{Se}$, tradicionalmente, essa última medida só era eficaz para transformar os "proibidos de permanecer" que a desrespeitavam em informantes policiais, o "afastamento" abria caminho para novas partidas forçadas para a Argélia. As proibiçôes incidiam mais frequentemente apenas para a região parisiense, mas podiam ser estendidas a todo o território francês.

De modo geral, por problemas orçamentários, esses proibidos de permanecer não foram levados de volta para a Argélia. Por outro lado, os pedidos de autorização de viagem eram às vezes utilizados para favorecer a "eliminaçáo" de indivíduos fichados na categoria "muito perigosos". Esse procedimento respondia à necessidade de limitar os custos da repressão, visto que os interessados financiavam suas próprias viagens. Quando pediam para voltar à Argélia e protocolavam seus dossiês nas delegacias de suas localidades, a autorização de viagem lhes era concedida e identificada com um número com a menção do departamento de residência na metrópole. Esse sinal permitia a prisão no momento da chegada à Argélia. Quando tudo funcionava corretamente, a pessoa em questão havia assim pago sua viagem para um campo argelino no qual ela se descobria confinada. Esse procedimento permaneceu em vigor entre agosto de 1957 e abril de 1959. Alguns "incidentes lamentáveis" encerraram essa experiência: ocorreu, por exemplo, que indivíduos assinalados fossem e voltassem sem serem perturbados ou que pessoas fossem presas, sem razão, quando de seu desembarque na Argélia. Em seguida, "a não ser por fortes razões humanitárias", tratadas em nível ministerial, os pedidos de saída do território francês não foram mais concedidos aos fichados $\mathrm{Z} .{ }^{27}$

$\mathrm{Na}$ Argélia, as autoridades locais, embora dotadas de poderes de polícia ampliados e reforçados pelos efetivos do exército, não tinham interesse em que os mais aguerridos militantes frontistas fossem concentrados em seu território, mesmo presos em campos - que se mostravam verdadeiras escolas de formação de quadros do FLN. Ao passo que, ao longo de vários anos, elas foram amplamente acusadas

\footnotetext{
${ }^{24}$ Arquivos Nacionais (NA) F1A 5134.

${ }^{25}$ DUBOIS, André-Louis; SERGENT, Pierre. Le malentendu algérien. 12 ans après. Paris: Fayard, 1972. p. 106-107.

${ }^{26}$ Circular de 15 de outubro de 1958, op. cit.

${ }^{27}$ Telegramas secretos do ministro do Interior, 7 de janeiro e 28 de abril de 1959, Arquivos da Prefeitura de Polícia (APP), HA 8.
} 
de incentivar a emigração para a metrópole dos "maus elementos" dos quais queriam se livrar, elas tiveram, por sua vez, que se confrontar com chegadas indesejáveis. Essas lutas de influência entre administraçôes metropolitanas e argelinas integram as razóes que explicam o fato de que, durante toda a guerra da Argélia, os circuitos da repressão administrativa e jurídica tenham conhecido diversas inflexões.

\section{Permanências e evoluções dos circuitos repressivos ${ }^{28}$}

No início da guerra de independência, esses circuitos terminavam quase sistematicamente além do Mediterrâneo. Para as forças da ordem, a Argélia era, com efeito, a saída natural para reprimir a vinda de "indesejáveis" que não deveriam ter deixado seus departamentos de origem. Acima de tudo, os meios jurídicos de repressão eram ali mais amplos que os meros expedientes do Código penal e do Código de instrução criminal, aos quais as forças da ordem metropolitanas deveriam se conformar. A cooperação com juízes da Argélia permitia contornar esses limites. A partir de 1957, foram lançadas operações em plano nacional, com o objetivo de processar na justiça argelina militantes do FLN da metrópole, com base no delito de atentado contra a segurança exterior do Estado e em suas ligaçóes (financeiras, especialmente) com uma organização cujos delitos além do Mediterrâneo eram objeto de processos judiciais. Detidos com base em cartas rogatórias expedidas por juízes de Argel, militantes parisienses foram assim transferidos para a Argélia. Alguns desses acusados foram aí presos, outros tiveram seus processos extintos por falta de justa causa e foram confinados em um dos campos já abertos, mas a maioria não demorou a voltar para a metrópole. A fragilidade dos elementos jurídicos que embasavam seus processos em um tribunal argelino, as sucessivas liberaçôes de campos superlotados, as reticências das autoridades dos departamentos argelinos em acolher esses suspeitos jogaram a favor dos retornos. O relativo fracasso de uma exportação da repressão em âmbito colonial incitou as autoridades policiais a pleitear um reforço de suas prerrogativas e das possibilidades de repressão administrativa e judicial na metrópole.

As repetidas prorrogaçóes dos prazos de prisão temporária e das possibilidades de inspeção - principalmente noturna - sem controle de um juiz de instruçáo vieram reforçar consideravelmente o arsenal da polícia. ${ }^{29}$ Graças a alíneas da portaria de 7 de outubro de 1958 relativas à internação administrativa, as forças da ordem foram cada vez mais liberadas de qualquer controle e efeito judicial. Para as autoridades policiais, o encarceramento nos campos funcionava, com efeito, como sanção ideal. Essa falta de instruçôes e processos judiciais permitia que os casos conduzidos com absoluto desrespeito dos procedimentos legais se traduzissem, não obstante, em prisão dos principais acusados. Somente os processos para os quais as regras formais haviam sido minimamente levadas em consideraçáo e provas de pertencimento ao FLN ou de participaçáo em crimes comuns (violências, extorsão...) haviam sido reunidas foram levados a tribunais judiciários. Desde 8 de outubro de 1958, uma portaria havia, com efeito, ampliado a possibilidade de instaurar processos na justiça militar metropolitana. Esta intervinha praticamente apenas na etapa do julgamento e, a partir de 1960, a instrução foi totalmente deixada nas mãos do poder policial..$^{30}$ Embora as autoridades policiais esperassem maior severidade dos Tribunais Permanentes das Forças Armadas (TPFA), suas expectativas foram, em parte, frustradas. Apesar de apenas os casos mais graves terem sido conduzidos aos TPFA, estes nem sempre se consideravam competentes e suas sentenças não eram, em

\footnotetext{
${ }^{28}$ Essa parte do texto é baseada no exame dos arquivos da repressão aos nacionalistas argelinos em Seine-et-Oise, conservados nos Arquivos departamentais de Yvelines. AD 78 1W 511 a $1 \mathrm{~W} 547$.

${ }^{29}$ BOITTIAUX, Stéphane. La Procédure de répression des infractions terroristes depuis le 30 octobre 1954. Thèse (droit) — Université de Paris, Paris, 1962.

${ }^{30}$ Portaria 60-520 de 3 de junho de 1960. Sobre esse tema, ver: BERLIERE, Jean-Marc. Policiers et pouvoir politique en période de crise: la guerre d'Algérie (1958-1962). In: BERLIERE, J.-M. et al. (Dir.). Etre policier: les métiers de police(s) XVIIIe.-XXe. siècle. Rennes: PUR, 2008. p. 523-541.
} 
média, muito diferentes das dos tribunais civis. ${ }^{31} \mathrm{O}$ caráter sumário dessa justiça não deixava, entretanto, de preocupar os defensores dos direitos humanos: acontecia de, em apenas uma tarde, os juízes militares condenarem à morte vários réus. ${ }^{32}$ Esses julgamentos expeditos incitavam a Prefeitura de Polícia a solicitar que um número cada vez maior de casos pudesse ser diretamente julgado nesses tribunais militares. ${ }^{33}$

O suposto laxismo da justiça, que estava na origem dessas inovaçóes jurídicas e da expansão inédita dos poderes policiais, estava entretanto longe de ser demonstrado. Ao longo de toda guerra da Argélia, em média mais de 10 mil argelinos foram detidos em prisóes metropolitanas, as quais não teriam podido suportar um novo aumento da população carcerária. ${ }^{34}$ Talvez tenha sido por isso, ou porque náo desejavam se afastar de seu estrito mandato profissional e não incomodar o governo, que os juízes nunca se interessaram pelas condições da internação administrativa. Em média, esses confinamentos em campos atingiram cerca de 5 mil pessoas apenas nos Cars, ${ }^{35}$ ou seja, novamente o total de vagas disponíveis. Quanto ao número de pessoas detidas em centros de triagem, ele é desconhecido; e a duração da internação era bem mais dependente das instalaçôes disponíveis e das possibilidades de confinamento nos Cars do que do limite de quinze dias imposto pelos textos reguladores. ${ }^{36}$

Essas dificuldades logísticas e, mais ainda, as acusaçóes levantadas contra os militantes afastados dos grandes centros urbanos, suspeitos de propagar a influência do FLN em cidades ou nas áreas rurais em que estavam confinados, levaram a polícia a retomar as estratégias de deportação. $\mathrm{O}$ caráter inelutável da independência argelina fez com que deixassem de se colocar os problemas políticos causados pelo envio para além do Mediterrâneo dos "terroristas" detidos na metrópole. A partir de 1961, interessava apenas a "eliminação dos indesejáveis" cuja presença na França não era bem-vinda. A sequência de prisôes realizadas depois de 17 de outubro de $1961^{37}$ é sintomática dessa evolução: para além da internação de cerca de 15 mil manifestantes em campos improvisados, como o Centro de Identificação de Vincennes, o Palais des Sports, o estádio de Coubertin, o Parque de Exposiçóes, nos quais inúmeras violências foram cometidas, nenhuma medida legal — por prisão — ou administrativa — por confinamento - foi aplicada. Em algumas semanas, mais de 1.500 argelinos foram entáo "expulsos para seu aduar de origem" ${ }^{38} \mathrm{O}$ caráter excepcional dessas manifestaçóes e de sua repressão permitiu colocar em prática aquilo que as forças policiais exigiam havia anos: expulsar, sem outra forma de processo, os "franceses muçulmanos da Argélia", cuja cidadania nunca se preservara das medidas policiais praticadas no mundo colonial ou daquelas aplicadas aos estrangeiros da metrópole.

\footnotetext{
${ }^{31}$ Relatório do gabinete do Ministério do Interior aos diretores da Prefeitura de Polícia e da Segurança Nacional, 18 de maio de 1960, APP HA 65.

${ }^{32}$ Entrevista com Henri Leclerc (advogado, colaborador de Yves Dechezelle e Pierre Stiebe, entre 1956 e 1959), Paris, 19 de maio de 2005. Ele menciona aqui o TPFA do Cherche-Midi, em Paris.

33 Para exemplos de divisões e disputas de competência entre jurisdiçóes civis e militares, ver: DEPERCHIN, Annie; LECOMPTE, Arnaud. Les crimes commis par les algériens en métropole devant la cour d'assises du Nord, $1954-1962$. In: AFHJ. La justice en Algérie 1830-1962, op. cit. p. 257-270.

${ }^{34}$ Dados disponíveis nas atas das reunióes dos CTAM (1958-1962), NA F1A 5014. Esses cômputos misturam presos comuns e presos políticos. No final de 1962, um pouco mais de 3 mil argelinos permaneciam presos na metrópole.

${ }^{35} \mathrm{Nas}$ atas dos CTAM essa rubrica só apareceu no final de 1959, quando o número de internados atingiu seu pico (5.700) para se estabilizar, em seguida, em um pouco menos de 5 mil, declinando depois rapidamente no quarto trimestre de 1961. ${ }^{36}$ Os registros policiais dos internados no quartel Noailles em Versailles (centro de triagem para o Seine-et-Oise) mostram que alguns entre eles ali permaneciam além da duração legal, mas raramente mais do que alguns dias, devido à superpopulação. A partir de 1959, com a abertura do Centro de identificação de Vincennes (CIV), a Prefeitura de Polícia passou a dispor de melhores recursos e alguns internados permaneceram detidos por vários meses. Entrevista com Saad Abssi (Gennevilliers, 3 de outubro de 2007), que permaneceu por dois meses no CIV, no início de 1960.

${ }^{37}$ Nesse dia, várias dezenas de argelinos que se manifestavam pacificamente contra a instauração de um toque de recolher aplicado exclusivamente à população proveniente da Argélia foram mortos sob os golpes e balas da polícia parisiense. Essa repressão foi objeto de uma verdadeira "mentira de Estado". HOUSE, Jim; MACMASTER, Neil. Paris 1961, op. cit.

${ }^{38}$ AMIRI, Linda. La bataille de la France: la guerre d'Algérie en métropole. Paris: Robert Laffont, 2004. p. 167-170.
} 